\title{
Trends in Polydrug Use Among Ecstasy-Related Ambulance Attendances in Melbourne, 2000 to 2009
}

\author{
Paul McElwee and Shelley Cogger
}

Turning Point Alcohol and Drug Centre, Fitzroy, Victoria, Australia

Keywords: Mdma, ecstasy, polydrug, acute, distress.

\section{INTRODUCTION}

Ambulance attendances at drug-related events provide rich and timely indicators for the monitoring of trends relating to alcohol and other drug use and characteristics of drug-related harms. Previous research [1,2] has shown that polydrug use among ecstasy users has increased over time, particularly the use of ecstasy in combination with alcohol, contributing to greater drug-related harms.

\section{AIM}

This paper examines ten year trends in patterns of polydrug use among ecstasy-related cases attended by ambulance in metropolitan Melbourne. Demographic and drug involvement characteristics of these cases are compared, with changes over time explored.

\section{METHOD}

Data were derived from the Ambo Project, a collaborative project between Turning Point Alcohol and Drug Centre and Ambulance Victoria. The Ambo Project collates information routinely recorded in patient care records by paramedics where the consumption of any drug significantly contributes to the reason for the ambulance attendance. As such, this sample is not representative of all ecstasy users in Melbourne, rather only those who experienced an adverse event from their drug use and who required paramedic care. All ecstasy-related ambulance attendances $(\mathrm{N}=2,897)$ from the 2000 to 2009 calendar years were selected for analysis.

\section{RESULTS}

During the 10 year period 2000 to 2009 , almost twothirds $(61 \%)$ of patients involved in ecstasy-related attendances were male, with a median age of 22 years (interquartile range 19-27). Alcohol was by far the most

*Address correspondence to this author at the Turning Point Alcohol and Drug Centre, Fitzroy, Victoria, Australia; Tel: (+43) 384138410;

E-mail: shelleycogger@bigpond.com common drug used in conjunction with ecstasy $(59 \%$ of cases). The four most common illicit drugs co-involved in ecstasy-related cases were amphetamines $(22 \%)$, gammahydroxybutyrate (GHB) $(12 \%)$, cannabis $(10 \%)$ and cocaine $(5 \%)$. With the exception of benzodiazepines $(5 \%)$, the frequency of pharmaceutical medication involvement was very low. Over the 10 year period examined, the proportion of cases where ecstasy was the only drug involved declined from 34 per cent in 2000 to 11 per cent in $2009(p<0.001)$. By contrast, the proportion of cases where two or more other drugs were co-involved with ecstasy increased from 22 per cent to 40 per cent $(p=0.001)$. Comparing events from 2000 and 2001 with events from 2008 and 2009, alcohol and GHB were the two drugs that were significantly more likely to be involved in ecstasy-related ambulance attendances $(\mathrm{RR}=1.5$, $95 \% \mathrm{CI}=1.245,1.797 ; \mathrm{RR}=6.71,95 \% \mathrm{CI}=3.127,14.418$, respectively). Heroin was less likely to be involved ( $\mathrm{RR}=0.43,95 \% \mathrm{CI}=0.232,0.801)$.

\section{DISCUSSION AND CONCLUSION}

Polydrug use among ecstasy users attended by ambulance in Melbourne increased over the 10 year period presented. However, the statistically significant trends in the drugs used concurrently with ecstasy were consistent with trends in drug-related events that did not involve ecstasy, suggesting that increases in the use of these drugs were not specific to ecstasy users alone.

\section{ACKNOWLEDGEMENTS}

Mental Health, Drugs and Regions Division, the Victorian Government Department of Health.

\section{REFERENCES}

[1] Topp L, Hando J, Degenhardt L, Dillon P, Roche A, Solowij N. Ecstasy Use in Australia NDARC Technical Report NO. 39. Sydney: National Drug and Alcohol Research Centre, University of New South Wales 1998.

[2] Kong F, Dietze P, McElwee P. Victorian Trends in Ecstasy and Related Drug Markets 2009. Finding from the Ectasy and Related Drugs Reporting System (EDRS). Australian Drug Trends Series No. 49: National Drug and Alcohol Research Centre, University of New South Wales 2010. 